\title{
Pengaruh Jenis Gelombang Singkat Dan Level Dekomposisi Gelombang Singkat Terhadap Pemampatan Citra Satelit
}

\author{
Tri Handayani \\ Program Studi Informatika, Sekolah Tinggi Teknologi Dumai \\ Jl. Utama Karya Bukit Batrem II Dumai \\ e-mail: trihandayani.stt@gmail.com
}

\begin{abstract}
ABSTRAK
MODIS merupakan salah satu aplikasi bidang penginderaan jauh (Remote Sensing). Data citra penginderaan jarak jauh sering menghadapi masalah penyimpanan dan transmisi data citra karena terbatasnya bandwidth, waktu pengiriman data dan peningkatan resolusi spasial. Penelitian ini bertujuan untuk menganalisa pengaruh pengaruh jenis gelombang singkat dan level dekomposisi gelombang singkat terhadap pemampatan citra satelit. Gelombang singkat yang digunakan adalah Haar, Coiflet_1, Coiflet_2, Symlet_1, Symlet_2, sedangkan level dekomposisi yang digunakan yaitu, level 3,4 dan 5. Dari pengujian dapat disimpulkan bahwa gelombang_singkat Coiflet_2 dan Symlet 5 memberikan nilai tertinggi untuk masing-masing level dekomposisi pada citra yang sama yaitu MOD03.
\end{abstract}

Kata kunci: MODIS, Gelombang singkat, Citra satelit

\begin{abstract}
MODIS is one of the application areas of remote sensing (Remote Sensing). Remote sensing image data often face the problem of storage and transmission of image data due to the limited bandwidth, data delivery time and improved spatial resolution. This research aims to analyze the influence of the influence of the type of short wave and short wave decomposition level against hardening of the satellite imagery. Short wave is Haar, Coiflet_1, Coiflet_2, Symlet_1, Symlet_2, whereas the level of decomposition used i.e., 3.4 and 5 levels. From testing it can be concluded that the gelombang_singkat Coiflet_2 and Symlet 5 provide the highest value to each level of decomposition on the same image that is MODO3.
\end{abstract}

Keywords: MODIS, Short wave, Satellite imagery

UNITEX Vol 11 No.2 Juli - Desember 2018 | p-ISSN 2089-3957 | e-ISSN 2580-2585 


\section{Pendahuluan}

Penginderaan jauh merupakan teknologi yang sangat dibutuhkan untuk negara maju dan berkembang. Penginderaan jauh biasa digunakan untuk memantau dan mendapatkan informasi atau data mengenai kondisi fisik suatu benda tanpa harus bersentuhan langsung dengan objek tersebut. Salah satu teknologi penginderaan jauh adalah satelit Terra MODIS. MODIS merupakan salah satu aplikasi bidang penginderaan jauh (Remote Sensing). MODIS (Moderate Resolution Imaging Spectroradiometer) merupakan program yang menggunakan sensor pada dua satelit yang masing-masing memberikan lingkup cakupan harian bumi. Menurut pendapat Prasasti (2010), Satelit Terra yang membawa sensor Modis (Moderate resolution imaging spectroradiometer) merupakan satelit pengamatan lingkungan yang dapat digunakan untuk ekstraksi data suhu permukaan yang bersifat regional.

Sensor MODIS adalah salah satu sensor utama yang dibawa Earth Observing System (EOS) Terra Satellite, yang merupakan bagian dari program antariksa Amerika Serikat, National Aeronautics and Space Administration (NASA). Satelit yang diluncurkan pada tahun 1999 ini, kemudian disempurnakan dengan satelit Aqua yang diluncurkan pada tahun 2002. Gelombang-singkat adalah suatu fungsi matematika yang membagi data menjadi beberapa komponen yang frekuensinya berbeda, kemudian mempelajari setiap komponen dengan resolusi yang cocok untuk setiap ukuran, (Santoso, et.al, 2010). Transformasi gelombang-Singkat memiliki keuntungan disaluraningkan transformasi Fourier untuk merepresentasikan fungsi yang memiliki diskontinuitas dan kenaikan atau penurunan yang tajam, dan untuk secara akurat mendekomposisi dan merekonstruksi sinyal non-periodik dan/atau sinyal non stationer.

Secara singkat, dalam transformasi wavelet, pertama-tama Sebuah sinyal akan dilewatkan pada rangkaian filter lolos tinggi dan filter lolos rendah, kemudian setengah dari masing-masing keluaran diambil sebagai sampel melalui operasi sub sampling. Proses ini disebut dekomposisi dan prosedur ini diulang sampai proses dekomposisi yang diinginkan. Penelitian ini bertujuan untuk menganalisa pengaruh pengaruh jenis gelombang singkat dan level dekomposisi gelombang singkat terhadap pemampatan citra satelit. Gelombang singkat yang digunakan adalah Haar, Coiflet_1, Coiflet_2, Symlet_1, Symlet_2, sedangkan level dekomposisi yang digunakan yaitu, level 3, 4 dan 5 .

UNITEX Vol 11 No.2 Juli - Desember 2018 | p-ISSN 2089-3957 | e-ISSN 2580-2585 


\section{Metode Penelitian}

Bahan yang digunakan dalam penelitian ini adalah citra satelit Terra MODIS dengan ukuran piksel 512 x 512. Peralatan minimal yang digunakan adalah komputer dengan spesifikasi procesor core i5 $2.50 \mathrm{GHz}$, 1TB HDD, 8 GB DDR3, Monitor 14". Perangkat lunak yang digunakan dalam penelitian ini adalah Sistem operasi windows dengan paket program Matlab R2018a.

Tabel 1. Data Citra satelit MODIS

\begin{tabular}{|c|c|c|c|}
\hline No & Tanggal & Citra & Nama File \\
\hline 1 & 30 April 2018 & & MOD01 \\
\hline 2 & 03 Mei 2018 & & MOD02 \\
\hline 3 & 07 Mei 2018 & & MOD03 \\
\hline & & & \\
\hline
\end{tabular}

\section{Hasil dan Pembahasan}

\section{Gelombang-singkat terhadap PSNR dan MSE}

PSNR digunakan untuk mengkuantifikasi kualitas citra, dimana fungsi gelombang singkat akan semakin baik jika nilai PSNR yang dihasilkan besar, karena hal ini bisa menunjukkan kemiripan antara citra asli dan citra rekonstruksi serta citra yang dihasilkan lebih baik.

$$
P S N R=10 \log _{10} \frac{255^{2}}{M S E}
$$

UNITEX Vol 11 No.2 Juli - Desember 2018 | p-ISSN 2089-3957 | e-ISSN 2580-2585 
MSE merupakan rata-rata selisih kuadrat dari nilai kesalahan. Persamaan MSE yang digunakan adalah

$$
M S E=\frac{1}{M N} \sum_{y=1}^{M} \sum_{x=1}^{N}\left[I(x, y)-I^{\prime}(x, y)\right]^{2}
$$

Dimana:

$\begin{array}{lll}\mathrm{MSE} & = & \text { Mean Square Error } \\ \mathrm{M}, \mathrm{n} & = & \text { Ukuran Citra } \\ \mathrm{I}(\mathrm{x}, \mathrm{y})= & \text { Nilai intensitas piksel citra asli } \\ \mathrm{I}(\mathrm{x}, \mathrm{y})= & \text { Nilai intensitas piksel citra hasil rekonstruksi }\end{array}$

Tabel 2. Hasil PSNR untuk level dekomposisi $=3$

\begin{tabular}{|c|c|c|c|}
\hline $\begin{array}{c}\text { Gelombang- } \\
\text { singkat }\end{array}$ & MOD01 & MOD02 & MOD03 \\
\hline Haar & 19.368 & 19.422 & 20.162 \\
\hline Coiflet_1 & 19.638 & 19.689 & 20.552 \\
\hline Coiflet_2 & 19.731 & 19.762 & 20.708 \\
\hline Symlet_2 & 19.368 & 19.442 & 20.162 \\
\hline Symlet_5 & 19.722 & 19.798 & 20.694 \\
\hline
\end{tabular}

Tabel 2 menunjukkan nilai hasil rekonstruksi tertinggi adalah gelombang singkat adalah gelombang singkat Coiflet_2 untuk citra MOD03 dengan nilai 20.708. 


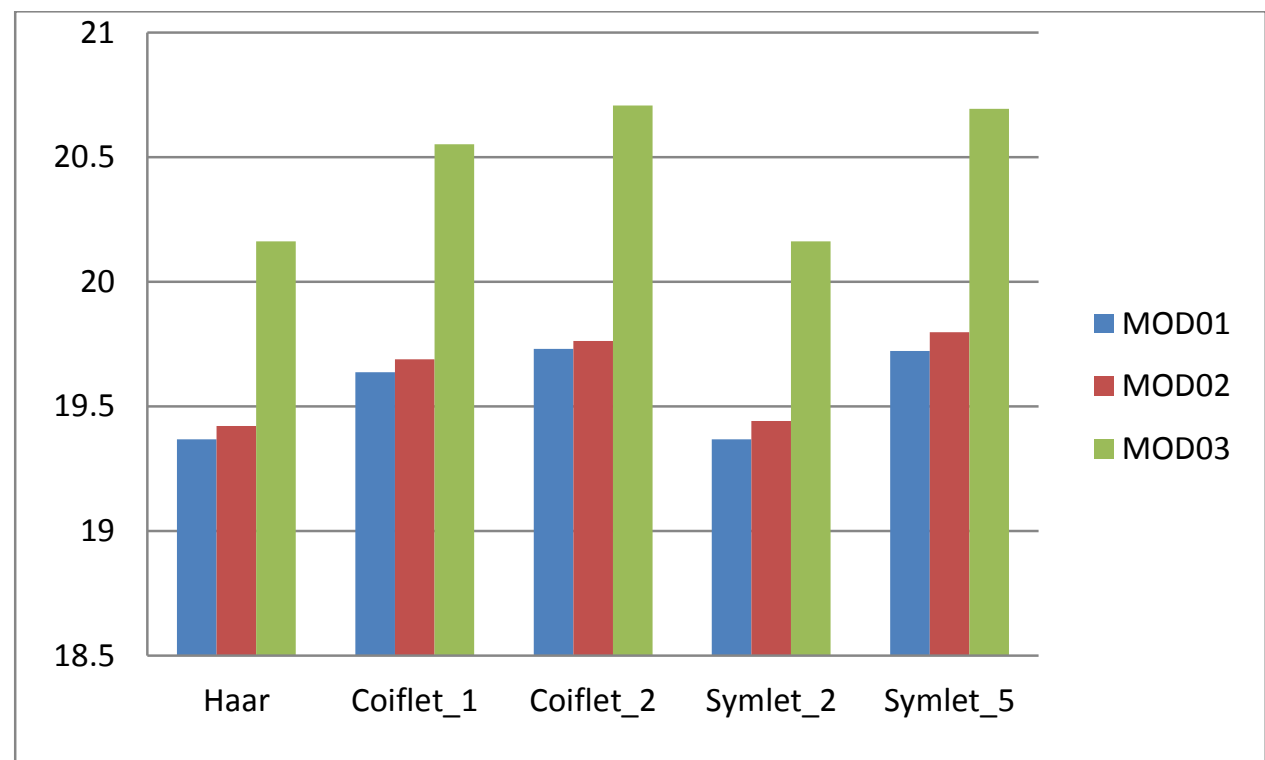

Gambar 1. Gelombang-singkat terhadap PSNR pada level dekomposisi = 3

Tabel 3. Hasil PSNR untuk level dekomposisi $=4$

\begin{tabular}{|c|c|c|c|}
\hline $\begin{array}{c}\text { Gelombang- } \\
\text { singkat }\end{array}$ & MOD01 & MOD02 & MOD03 \\
\hline Haar & 18.325 & 18.336 & 18.794 \\
\hline Coiflet_1 & 18.772 & 18.689 & 19.434 \\
\hline Coiflet_2 & 18.951 & 18.867 & 19.792 \\
\hline Symlet_2 & 18.325 & 18.336 & 18.794 \\
\hline Symlet_5 & 18.908 & 18.847 & 19.792 \\
\hline
\end{tabular}

Tabel 3 menunjukkan nilai hasil rekonstruksi tertinggi adalah gelombang singkat adalah gelombang singkat Coiflet_2 dan Symlet_5 untuk citra MOD03 dengan nilai 19.792 


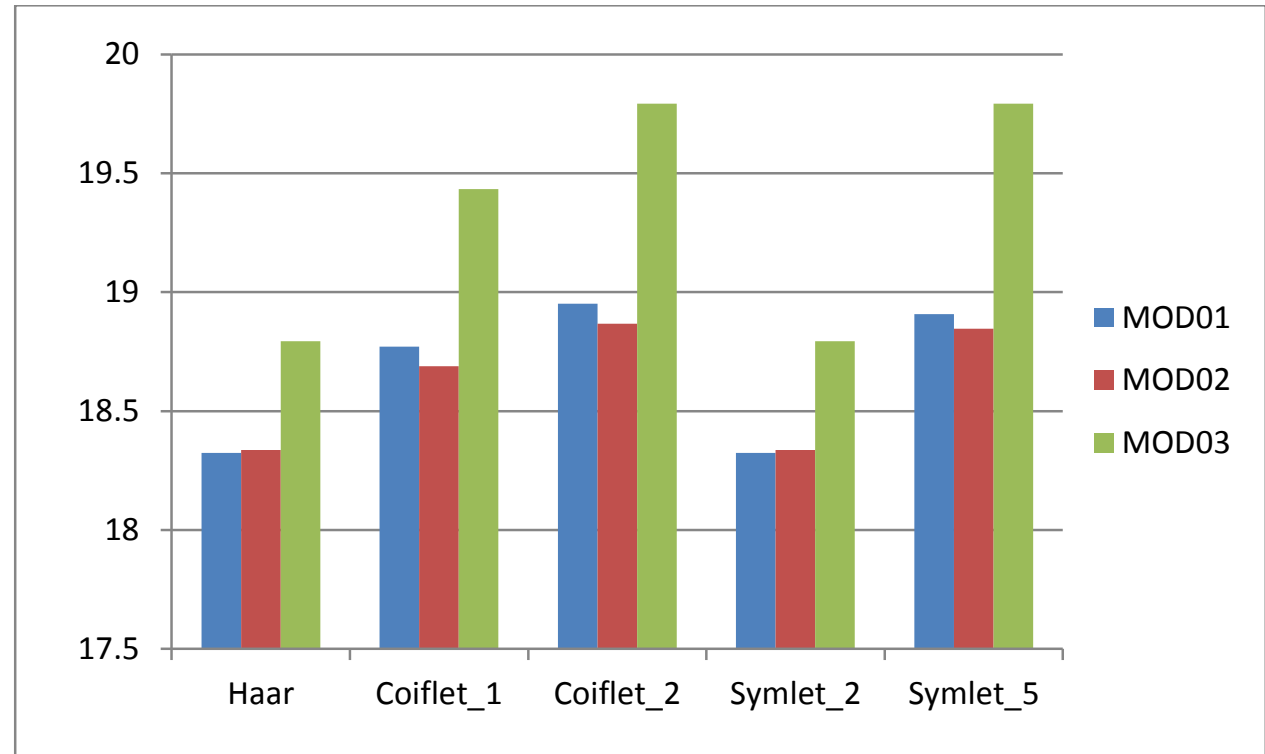

Gambar 2. Gelombang-singkat terhadap PSNR pada level dekomposisi $=4$

4. Hasil PSNR untuk level dekomposisi $=5$

\begin{tabular}{|c|c|c|c|}
\hline $\begin{array}{c}\text { Gelombang- } \\
\text { singkat }\end{array}$ & MOD01 & MOD02 & MOD03 \\
\hline Haar & 17.186 & 17.162 & 17.436 \\
\hline Coiflet_1 & 17.791 & 17.588 & 18.191 \\
\hline Coiflet_2 & 18.055 & 17.851 & 18.776 \\
\hline Symlet_2 & 17.186 & 17.162 & 17.436 \\
\hline Symlet_5 & 18.054 & 17.819 & 18.587 \\
\hline
\end{tabular}

Tabel 4 menunjukkan nilai hasil rekonstruksi tertinggi adalah gelombang singkat adalah gelombang singkat Coiflet_2 untuk citra MOD03 dengan nilai 18.776. 


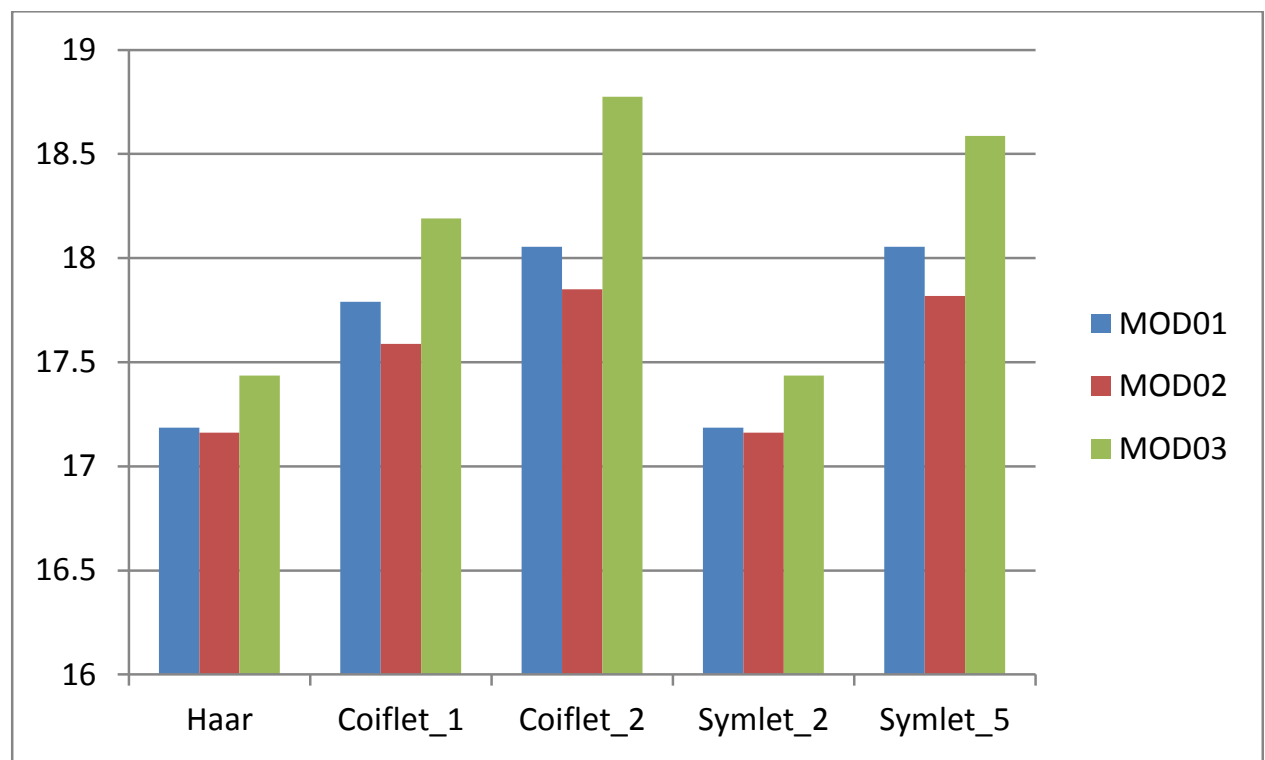

Gambar 3. Gelombang-singkat terhadap PSNR pada level dekomposisi $=5$

\section{Kesimpulan}

Dari pengujian dapat disimpulkan bahwa gelombang_singkat Coiflet_2 dan Symlet 5 memberikan nilai tertinggi untuk masing-masing level dekomposisi pada citra yang sama yaitu MOD03. Level dekomposisi $=3$ nilai tertinggi pada GS Coiflet_2 dengan nilai 20.708, level dekomposisi = 4 pada GS Coiflet_2 dan Symlet_5 dengan nilai 19.792 sedangkan level dekomposisi = 5 pada GS Coiflet_2 dengan nilai 18.776. Semakin tinggi nilai PSNR semakin tinggi kemiripan citra.

\section{Daftar Pustaka}

Prasasti, I., Sambodo, K. A., \& Carolita, I. (2007). Pengkajian Pemanfaatan Data Terra-MODIS untuk ekstraksi Data Suhu Permukaan Lahan (SPL) berdasarkan beberapa algoritma. Jurnal Penginderaan Jauh dan Pengolahan Citra Digital, Vol. 4, No.1.

Gopi, N., \& A.S, S. (2017). Implementation of Lossless Image Compression on Satellite Image Using Microblaze Processor. International Journal of Engineering Trends and Technology (IJETT). 272-275.

UNITEX Vol 11 No.2 Juli - Desember 2018 | p-ISSN 2089-3957 | e-ISSN 2580-2585 
Kumar, V. S., \& Reddy, M. I. (2012). Image Compression Techniques by using Wavelet Transform. Journal of Information Engineering and Applications, Vol.2, No.5.

Santoso, A. J., Nugroho, L. E., Suparta, G. B., \& Hidayat, R. (2011). Color Image Compression Using Orthogonal Wavelet Viewed From Decomposition Level and Peak Signal to Noise Ratio. International Journal of Advanced Science and Technology, Vol. 31.

Samra, H. (2012). Image Compression Techniques. International Journal of Computer \& Technology, Volume 2 No.2.

Sutarno. (2010). Analisis Perbandingan Transformasi Wavelet pada Pengenalan Citra Wajah. Jurnal Generic, 15-21.

Anwar, K., Sugiharto, A., \& Sasongko, P. S. (2008). Kompresi Citra Medis Menggunakan Discrete Wavelet Transform (DWT) dan Embedded Zerotree Wavelet (EZW). Jurnal Matematika, 73-77.

Santoso, A. J., Soesianto, F., \& Dwiandiyanto, B. Y. (2010). Pemampatan Basis Data dan Pengenalan Pola Citra Satelit Untuk Deteksi Dini Bencana Alam. SESINDO 2009. ITS.

Munandar, T. A., Santoso, A. J., \& L, A. (2011). Analisa PSNR, Rasio Kompresi Warna dan MSE Terhadap Kompresi Image MEnggunakan 31 Fungsi Wavelet. Digital Information \& System Conference. 